\title{
Exploring differences in psychological well-being and self-regulated learning in university student success
}

\author{
Sarah K. Davis \& Allyson F. Hadwin ${ }^{1}$ \\ ${ }^{1}$ University of Victoria, Victoria, BC, Canada \\ Article received 30 October 2019 / Article revised 4 December 2020 / Accepted 5 December / Available online 25 January \\ 2021
}

\begin{abstract}
Worldwide, there are increasing concerns about postsecondary students' mental health and how student success is implicated. Previous research has established psychological well-being and self-regulated learning are important components of student success, however, there is a paucity of research examining the interplay between these factors during a semester-long course. In this study, 118 students in a learning-to-learn elective university course completed nine weekly online planning and reflection tools. Students planned for a study session, completed an academic engagement and a psychological well-being measure, then reflected on a challenge faced and described the strategy chosen to overcome that challenge. Findings revealed (a) students who reported always attaining their goals also reported higher overall psychological well-being, and (b) within-person patterns of psychological well-being and academic engagement over time may affect regulatory responses to challenge or vice versa. Implications for theory, research, and practice are discussed.
\end{abstract}

Keywords: Goal attainment; process mining; psychological well-being; selfregulated learning; student success. 


\section{Introduction}

University students' mental health is a growing concern globally. North American postsecondary students report: (a) feeling exhausted by academic work, and (b) experiencing levels of stress and anxiety compromising mental health, academic learning, and personal success (ACHA, 2018). One out of four Australian university students experiences high levels of distress (Larcombe et al., 2015), and in the UK, $78 \%$ of postsecondary students reported experiencing problems with their mental health in the past year (National Union of Students, 2015). Across Europe, findings are mixed: university students' mental health tends to be better than the rest of the general population, however more students are reporting struggling with mental illness in the past 15 years (Rückert, 2015). These high levels of distress could be due to any number of challenges at university. However, the consequences of poor mental health on postsecondary students is clear: mental health concerns are a common reason given by university students who take a temporary leave of absence or drop out altogether (Yorke \& Longden, 2008). Preventing this attrition is daunting because few students experiencing mental health challenges seek help (ACHA, 2018). In addition, the problems students experience at university may be compounded by the challenges they encounter while attempting to engage with and master coursework. Specifically, while completing coursework, students report encountering problems with motivation and beliefs, planning and goal setting, well-being, emotion, and cognition (Hadwin et al., 2019). These challenges interfere with student success at university. However, there is a paucity of research examining how academic challenges encountered during learning affect mental health at university.

\subsection{Mental health}

Mental health, distinct from mental illness, refers to a state of well-being in which individuals cope with stressors, work productively, and contribute to society (WHO, 2016). In Keyes' dual-continua model, mental illness and mental health do not exist as opposite ends of a single continuum, but rather as distinct, correlated axes suggesting mental health is a separate state (see Figure 1; Keyes, 2005, 2013). Including both hedonic (i.e., positive feeling defined as emotional well-being) and eudaimonic (i.e., positive functioning defined as psychological and social well-being) perspectives in defining mental health is vital for understanding overall human well-being (Deci \& Ryan, 2008). There are three factors in Keyes' mental health model: psychological, social, and emotional well-being (Keyes, 2002). In sum, mental health is how individuals perceive and evaluate their own affective states, and psychological and social functioning.

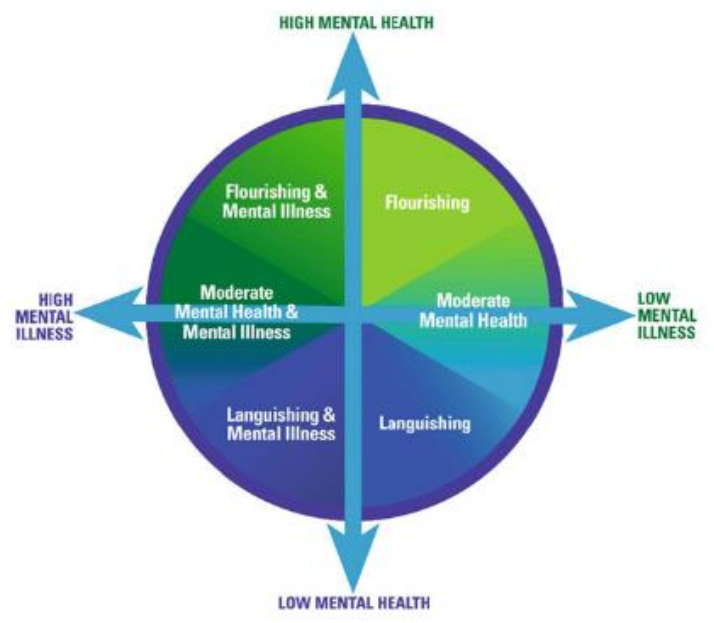

Figure 1. Keyes' dual-continua model of mental health. Figure from "Promoting and protecting positive mental health: Early and often throughout the lifespan," by C. L. M. Keyes in C. L. M. Keyes (Ed.), Mental well-being: International contributions to the study of positive mental health (p. 17), 2013, Springer Netherlands. Copyright 2013 by C. L. M. Keyes. Reprinted with permission. 


\subsection{Psychological well-being}

For this exploratory study, we focused on psychological well-being (PWB) as the mental health factor of interest because PWB may be particularly important to student success and learning at university (Howell, 2009). This is because PWB characterizes the process of living and functioning well and actualizing human potential (i.e., eudaimonia; Ryan et al., 2008) which are particularly relevant to university functioning. PWB captures myriad concepts related to eudaimonia, including selfacceptance, positive relations with others, personal growth, life purpose, autonomy, environmental mastery (Keyes, 2013; Ryff \& Keyes, 1995; Ryff \& Singer, 1998), and relatedness, competence, engagement, and meaning (Diener et al., 2010). The specific concepts captured by PWB may differ depending on what conceptualization and/or measure is used. For example, in self-determination theory, Ryan and Deci (2001) explain eudaimonic living is fostered by pursuing intrinsic goals, satisfying basic psychological needs for competence and relatedness, being mindful and acting with awareness, and behaving autonomously. This is in comparison to other conceptualizations, for example, Ryff \& Singer (1998) whose widely used six dimensions indicate the presence of PWB. In addition, others define psychological well-being as being synonymous with happiness (e.g., Hills \& Argyle, 2001), or hedonic well-being indicating positive or negative affect or satisfaction with life. As this study uses Keyes' theoretical framework, psychological well-being in this study is defined as how individuals perceive the quality of their functioning in life, or eudaimonia (Keyes, 2013).

The role of PWB is of particular interest in student success research due to the recent shift in the field from only focusing on symptoms of mental disorders at university (e.g., ACHA, 2018), to understanding the factors contributing to students' PWB at university. Previous research indicates students' high well-being in high school predicts high well-being in the first weeks of university, and well-being decreases during a university semester (De Coninck et al., 2019). In addition, students' optimism is the best predictor of high PWB and lower levels of psychological distress (Burris et al., 2009), and student involvement in campus organizations and sports has a positive effect on fourth year PWB (Kilgo et al., 2016). Current approaches to research on PWB contribute greatly to the understanding of PWB at university. However, gaps in the field include considering how PWB fluctuates over time at university and the interplay of PWB, learning, and student success.

\subsection{Student success and self-regulated learning at university}

Historically definitions of student success focus on attaining a degree at the institution of attendance (Kuh et al., 2007). Contemporary definitions of student success are moving from defining success only at the institutional level to defining success at the student level. A meta-analysis of student success research defined success in the first year of university through the three domains of critical thinking, academic achievement, and socio-emotional well-being (van der Zanden et al., 2018). This multidimensional view recognizes students may define success for themselves in different ways. Thus, this current study operationalizes student success at an even finer-grained level: student success is when students attain self-set goals (e.g., academic, social, etc.) to self-determined standards of excellence by exercising strategic metacognitive monitoring and control of behaviors, emotions, motivation, and cognition within and across study sessions.

Self-regulated learning (SRL) is vital for student success because self-regulation is ubiquitous. At university, self-regulating learners take control of their own learning, motivation, affect, and behaviors while striving to attain their own academic and personal goals (Schunk \& Greene, 2018; Zimmerman, 1989; Zimmerman \& Schunk, 2001). The vast amount of information and choices in university can easily become overwhelming and students need to be active participants in their learning by engaging in regulating their learning, rather than by being passive recipients of information (Pintrich, 2004). In SRL research, challenges provide opportunities for both researchers and students to examine regulated learning as students are trying to attain goals (Hadwin \& Winne, 2012). To become strategic learners, students (a) proactively take control of their learning by setting goals, (b) progressively develop 
metacognitive awareness, (c) monitor and evaluate their learning conditions, and (d) adapt their approaches when needed (Winne, 2001; Zimmerman, 1989). Increasing metacognitive knowledge and self-monitoring skills through SRL can help students overcome academic challenges and effectively develop coping strategies to deal with them (Zimmerman \& Martinez-Pons, 1990).

Challenges are central to university and may hinder or constrain PWB and/or learning, however limited research examines the interplay between SRL and PWB around academic challenges. From previous research on SRL and psychopathology at university, (a) students who experienced high levels of psychological distress may be unable to persist when they experience failure or challenges to complete academic tasks (Brackney \& Karabenick, 1995); and (b) medical students who report using more SRL strategies also reported lower rates of depression (Van Nguyen et al., 2015). In a study on mental health and SRL using Keyes' $(2002,2005)$ conceptualization found, students with flourishing mental health also had the highest levels of overall adaptive academic functioning, defined as having a growth mindset, setting mastery goals, not procrastinating, and having high self-control (Howell, 2009). Finally, students' use of effective motivation regulation strategies indirectly affected academic performance and emotional well-being (Grunschel et al., 2016). Salient components of PWB include a sense of autonomy and life purpose, and as such, goal setting and attainment are critical. For this reason, examining PWB and SRL may provide further insight into the specific role of PWB in student success.

\section{Purpose and research questions}

This study aimed to examine the interplay between PWB and SRL as students plan for and reflect on their approaches to attaining self-set academic goals over nine consecutive weeks. We had two research questions: (a) does PWB differ between groups of students with varying goal attainment?, and (b) how do patterns of regulation over the semester differ between a student who consistently attains weekly study goals (i.e., high goal attainment) and a student who does not (i.e., lowmoderate goal attainment)?Based on the findings from Howell (2009), we hypothesized students with higher goal attainment will also have higher PWB, and they will regulate their learning around challenges differently than students with lower PWB.

\section{Methods}

\subsection{Participants}

Students from across the university were enrolled in an undergraduate elective course on learning strategies for university success in the fall semester of 2017. This educational psychology course taught the theory, research and practice of strategic learning, motivation, and behaviour with a self-regulated learning lens framed around Winne \& Hadwin's (1998) SRL model. Students attended one 90-minute lecture and one 90-minute lab section each week and were enrolled in at least one other course concurrently. Consenting participants in this study were 140 students. We had two criteria for inclusion. First, students who missed $1 / 3$ or more of the weekly SRL diary tool $(n=$ 22) were excluded from analysis because weekly concurrent data from these students was too sparse to examine patterns in their psychological well-being, academic engagement, or goal attainment. Second, students were excluded from analysis if $50 \%$ or more of their weekly SRL diary tools were completed 
within 1 hour or less since this activity required them to plan for, conduct and then reflect upon a 1-2 hour academic study session. The remaining 118 students fit these criteria. Participants had a mean age of 19.12 years, $58 \%$ of students were female, $70 \%$ were first year students, and $90 \%$ of students reported English was their first language.

\subsection{Data}

\subsubsection{SRL Diary Tool}

The purpose of the weekly SRL diary tool was to encourage students to commit to one study session per week and practice engaging in a self- regulatory cycle to plan for, reflect on, and learn from each study session. Diary tools are a useful instrument for measuring SRL over time because they can help students raise their metacognitive awareness of their studying (Schmitz et al., 2011). A narrative response constructor in the weekly diary tool prompted students to identify and reflect on a main challenge encountered that week (see Figure 2).

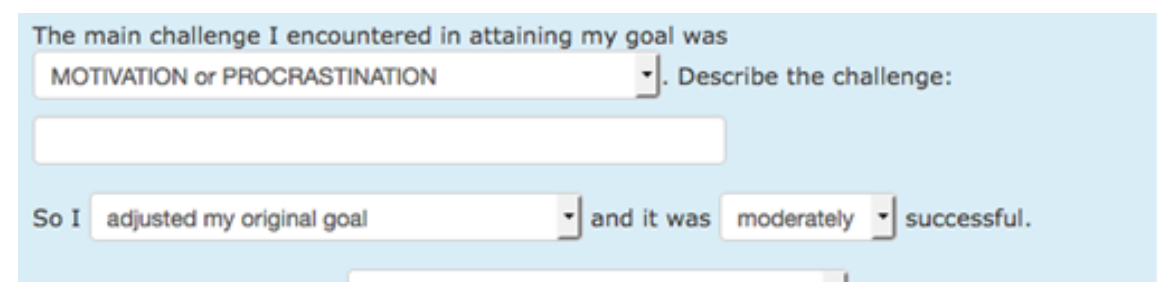

Figure 2. Items assessing students' metacognitive awareness of their weekly main challenge and their regulatory response to that challenge.

Students completed the SRL diary tool in two parts, planning and reflecting. In the planning session, the academic engagement and PWB measures create an opportunity for students to do an overall check-in on themselves for the previous week. To compute the group mean for academic engagement and PWB scores, student's weekly scores were averaged to compute one within-person average for each student, and these scores were averaged to create the group grand mean. For the academic engagement measure, students answered six questions either yes or no about their engagement in all their academic courses for the past week (see Appendix A). Items 1-4 captured four aspects of behavioural engagement and items 5 and 6 captured cognitive engagement. Cronbach's alpha was .64 for the academic engagement scale (see Fredericks et al., 2004). The psychological well-being measure (see Appendix A) was adapted from Rush \& Grouzet (2012) and has 10 items where students rated each item on a 6-point Likert scale from 1 not at all to 7 very much. Cronbach's alpha was .85 for the PWB scale in this study.

\subsubsection{Indicators of $S R L$}

This study uses students' goal attainment and the challenge and strategy reflection as indicators of SRL. For goal attainment, each week after completing the 1-2 hour study session, students reflected on their self-set goal and indicated if they (a) did attain, or (b) did not attain their goal. For analysis, a score of 1 was used to indicate the goal had been attained and 0 was used to indicate it had not. Taken from previous research on goal attainment in the online SRL diary tool (Hadwin et al., 2019), we divided students up into three groups based on their goal attainment score which was calculated by the proportion of weeks the goal was reported to have been attained. Natural breaks in the distribution of goal attainment proportions (see Figure 3) resulted in three groups: (a) low/moderate attainers reporting attaining goals $33-78 \%$ of the time $(n=49)$, (b) high attainers reported attaining goals $86-89 \%$ of the time $(\mathrm{n}=32)$, and (c) always attainers reported attaining their goals $100 \%$ of the time $(\mathrm{n}=$ 37). Descriptives for the three groups are reported in Table 1. 


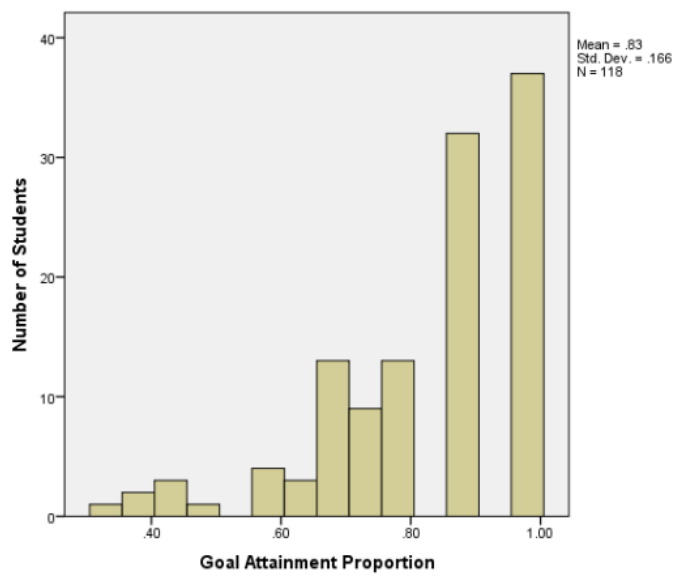

Figure 3. Histogram of within-person mean proportion of self-set goals reported attained over nine weeks used to create three goal attainment groups.

Table 1

Descriptives for the three goal attainment groups

\begin{tabular}{lccccc}
\hline $\begin{array}{c}\text { Goal Attainment } \\
\text { Group }\end{array}$ & $\mathrm{n}$ & $\begin{array}{c}\text { Overall PWB } \\
\text { mean(SD) }\end{array}$ & Final Exam & $\begin{array}{c}\text { Final Course } \\
\text { Grade }\end{array}$ & $\begin{array}{c}\text { Overall } \\
\text { Academic } \\
\text { engagement }\end{array}$ \\
\hline Low/Moderate & 49 & $45.27(8.77)$ & $72.88(11.91)$ & $73.62(10.46)$ & $4.38(.76)$ \\
High & 32 & $47.73(8.75)$ & $72.59(16.82)$ & $74.07(10.84)$ & $4.87(.57)$ \\
Always & 37 & $51.64(6.48)$ & $71.89(14.35)$ & $73.88(7.78)$ & $5.15(.55)$ \\
Overall & 118 & $47.93(8.49)$ & $72.49(14.03)$ & $73.83(9.73)$ & $4.75(.73)$ \\
\hline
\end{tabular}

For challenges and strategies, these lists were generated after reviewing and categorizing open ended text-based challenge statements and strategies identified by students in earlier iterations of the course (Hadwin et al., 2019). For analysis purposes, challenges were grouped into 10 distinct categories including: (a) motivation, (b) planning, (c) strategy, (d) cognition, (e) environment, (f) vocabulary and expression, (g) culture, (h) emotion, (i) mental health and well-being, (j) health and wellness, and (k) other challenge not in the list. Rather than asking about specific techniques or tactics (e.g., highlighting, elaborative interrogation, etc), strategy choices focused on types of regulatory actions. For analysis purposes, strategies were grouped into 9 categories including: (a) persisting, (b) goal management, (c) strategy adjustment, (d) help seeking, (e) emotion regulation, (f) changing effort, (g) task understanding, (h) passive strategies, and (i) other strategy.

\subsubsection{Academic Performance Variables}

Two academic performance variables were computed for the three groups. Students' final course grade reflects comprises coursework completed during the semester of the learning-to-learn course, including a final exam. The final exam tested students on their knowledge of course concepts through multiple choice questions and was worth $25 \%$ of their final course grade. Grades on both items could range from $0 \%$ to $100 \%$. 


\subsection{Procedures}

All procedures were approved by the institution's Human Research Ethics Board and all students used in data consented to participate through implied consent by enrolling in the course and not withdrawing from the research study. There was no incentive for consenting to participate in the research. Data were collected as part of regular course activities graded for participation but not for content. Participants completed part of the weekly SRL diary tool in their lab section and finished them independently for homework before the next lab meeting.

\section{Results}

RQ1: Does PWB differ between groups of students with varying goal attainment?

In examining the groups for differences in PWB, the low/moderate goal attainment group had the lowest PWB score of the three groups and was significantly different only from the always goal attainment group (see Table 4). PWB was positively correlated to academic engagement ( $r=.605, p<$ $.001)$ and goal attainment $(r=.414, p<.001)$, meaning that higher levels of PWB were associated with higher levels of academic engagement and goal attainment. Academic engagement was positively correlated to goal attainment $(r=.538, p<0.001)$, meaning that higher levels of academic engagement were associated with higher levels of goal attainment. A one-way analysis of variance (ANOVA) determined there were significant differences between the three goal attainment groups for PWB $(F(2,115) 6.497, p=.002)$. This corresponded to an effect size of $\eta^{2}=.10$ indicating $10 \%$ of the variance in PWB scores was predictable from goal attainment group membership. A Tukey post hoc test $(\alpha=.05)$ revealed the PWB score was significantly lower for the low/moderate goal attainment group $(\mathrm{M}=45.27)$ than the always goal attainment group $(\mathrm{M}=5.15)$. The high goal attainment group $(\mathrm{M}=$ 47.73) did not differ significantly from either group.

Table 2

Mean PWB scores for each goal attainment group

\begin{tabular}{llllll}
\hline Group Name & $\mathrm{n}$ & Mean PWB (SD) & 95\% CI & Minimum & Maximum \\
\hline Low/Moderate & 49 & $45.27(8.77)$ & $42.75-47.79$ & 26.50 & 63.75 \\
High & 32 & $47.73(8.75)$ & $44.57-50.88$ & 29.56 & 60.00 \\
Always & 37 & $51.64(6.48)$ & $49.48-53.80$ & 40.29 & 67.11 \\
Overall & 118 & $47.93(8.49)$ & $36.39-49.48$ & 26.50 & 67.11 \\
\hline
\end{tabular}

RQ2: How do patterns of regulation over the semester differ between a student who consistently attains weekly study goals (i.e., high goal attainment) and a student who does not (i.e., low-moderate goal attainment)?

The ANOVA established differences between the PWB of the low/moderate group and the always goal attainment group. Next, we examined within-person patterns of PWB, academic engagement, and SRL for two sample students. Process mining is a new method used to gain insight into students' regulatory patterns and processes (see Bannert et al., 2013). Previous research has used process mining maps to aggregate student data by groups, but they can also be used to map individual students' data over time to uncover patterns representative of dominant student profiles (e.g., Rogiers et al, 2020). Due to the highly individualized nature of the online SRL diary tool, we did not have expectations of "correct" sequences of student responses. For example, if a student reported a motivation challenge, there are several strategies they may have chosen rather than only one correct strategy to choose. Thus, we did not aggregate students' process mining maps but rather we chose one student from each group whose individual mean of PWB was the closest to the group mean and created a process 
mining map for each of these students. We hypothesized these students would show different patterns of regulating their learning over time. Videos 1 and 2 show the process mining maps for student LM (mean PWB $=45.22$ ) from the low/moderate group and student $\mathrm{AL}$ (mean PWB $=51.89$ ).

The process mining maps show each student's self-reported academic engagement, PWB, challenge (in capital letters), and weekly strategy over nine weeks. PWB mean scores were divided into three categories: low PWB $=10-30$, moderate $\mathrm{PWB}=31-50$, and high $\mathrm{PWB}=51-70$. Academic engagement was also divided into three categories: low engagement $=1-2$, moderate engagement $=3$ 4 , and high engagement $=5-6$. Challenges are reported in capital letters. Both challenges and strategies were grouped according categories outlined in 3.2.2 in this paper. As seen in the dynamic version of the map (see Video 1), each moving dot indicates the sequence of the four categories as selected each week by the student and the 9 weeks appear simultaneously. The green dot indicates the goal was attained and the red dot indicates the goal was not attained. Hovering over the dot will reveal the week of each individual dot. The darker blue colour of the box indicates the higher frequency of selection by the student and the numbers by the lines between boxes indicate the number of times a path occurred. For example, for Student LM, at the start of the video, the 3 weeks where the student had high engagement, the student attained all their goals. Student LM's most common challenge was motivation $(n=4)$ and the most common path was between moderate engagement and moderate PWB $(n=6)$. In Student AL's video (see Video 2), the video shows frequent high engagement with all goals attained. Student AL's most common challenge $(n=4)$ and the most common path was between high engagement and high PWB $(n=5)$.

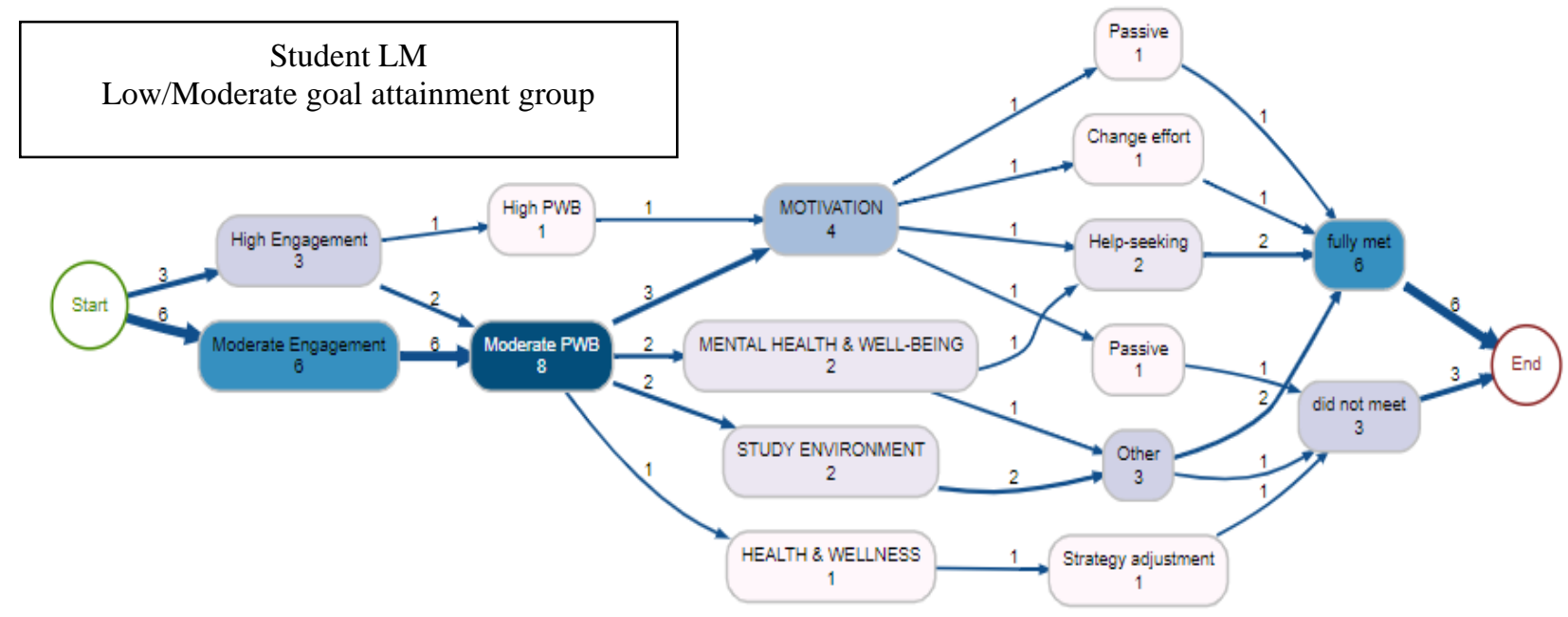

Video 1. Process mining map for Student LM from the low/moderate goal attainment group

Student LM from the low/moderate group began the course with high engagement and PWB, but strategy choices of passive and help-seeking led to frequent motivation challenges, leading to moderate engagement and PWB toward the end of the course (see Video 1). Student AL from the always group also began the course with high engagement and PWB, but the strategy choice of persist led to moderate PWB (see Video 2). When strategy, motivation, or cognition were the dominant challenges, strategies chosen by Student AL led to high engagement, followed by high PWB toward the end of the course. 


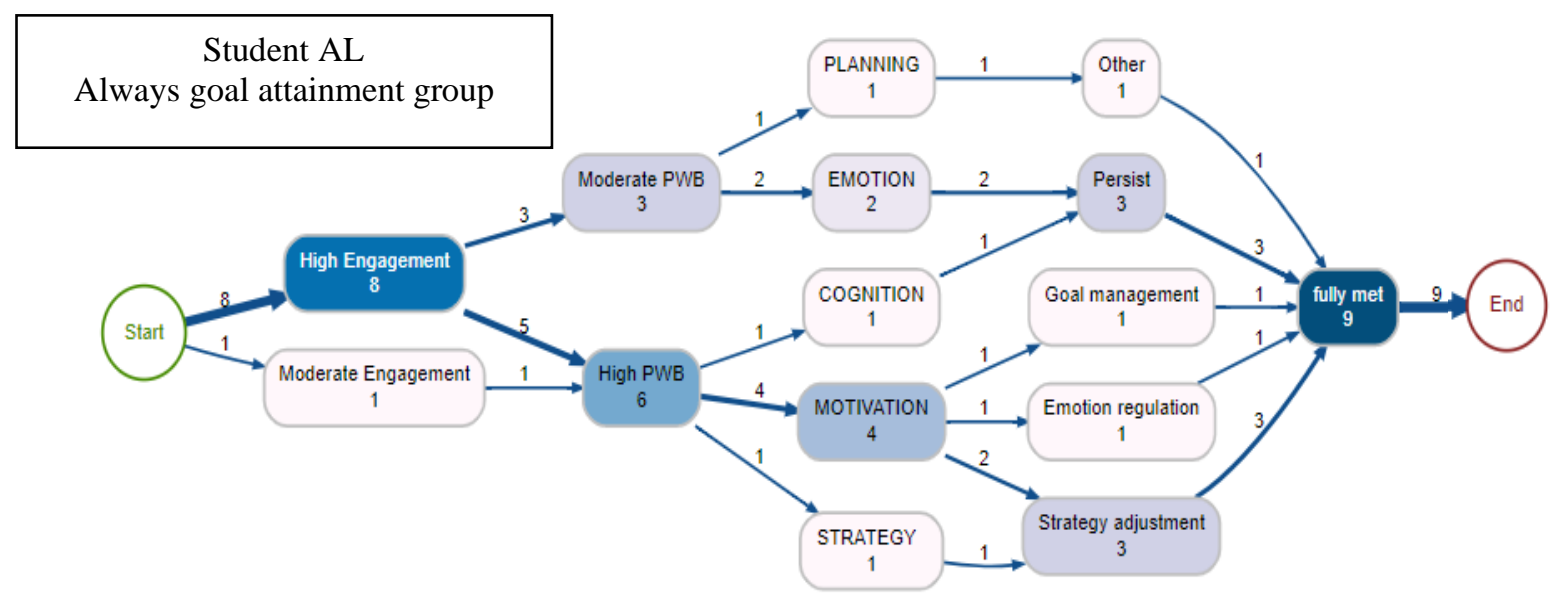

Video 2. Process mining map for Student AL from the always goal attainment group

\section{Discussion}

This study aimed to examine the interplay between PWB and SRL as students plan for and reflect on their approaches to attaining self-set academic goals over nine consecutive weeks. We used both between-person and within-person approaches. Two main findings from this study are highlighted: (a) students' between-person PWB differs according to self-reported goal attainment, and (b) students' within-person patterns of regulatory responses provide insight into the interplay between PWB and SRL. This study found students who reported always attaining their goals had higher PWB than students who reported low/moderate levels of goal attainment. This is consistent with Boudreaux \& Ozer's (2012) finding that students who have high goal attainment both report success in pursuing multiple goals and have high life satisfaction and positive affect (i.e., emotional well-being). The finding from this study adds to the student success literature that students who always attain their self-set study goals also have high PWB. Feeling purpose in life and attaining goals is a part of the six dimensions of PWB (Ryff \& Singer, 1998). Similarly, from an SRL perspective, attaining self-set goals indicates students are regulating their learning effectively. We did not specifically examine students' task perceptions or quality of the goals students' attained, two essential aspects of the phases of regulating learning (Hadwin \& Winne, 2012), therefore future research could examine how task perceptions and subsequent goal attainment are implicated in both academic engagement and PWB.

Our second main finding was within-person patterns of PWB and academic engagement over time may affect regulatory responses to challenge or vice versa. Regulatory responses in this study comprised the challenges and strategies students reported while attempting to attain self-set goals. Previous research examining SRL and mental health at one time point also found students with better mental health had a mastery-approach goal orientation (Howell, 2009). Examining the process maps of Student LM and Student AL indicates PWB and engagement may be interacting with challenges and strategies. For example, Student LM seemed to try a variety of strategies when they had a motivation challenge but continued to have motivation challenges during the semester, ending with moderate engagement and PWB compared to the start of the semester. Student AL also experienced motivation challenges but tried several other strategies and in turn experienced high engagement and high PWB consistently throughout the semester. Drawing on these findings, does high engagement or PWB fuel regulatory responses or do regulatory responses fuel high engagement or PWB? As SRL processes and strategies change over time and within-person, future research should continue to examine SRL and PWB or mental health as within-person processes. This will also allow for robust interventions based on students' individual patterns, rather than comparing students to each other. 


\subsection{Implications}

In SRL, metacognitive awareness is central to learning and student success. At university, students must contend with multiple goals (e.g., academic, social, financial) to attain success. This study contributes to theory by indicating high PWB may be advantageous for students regulating their learning, or vice versa. Personal growth, life purpose, and autonomy are some of the dimensions of PWB (Ryff \& Singer, 1998), therefore these larger-grained states may be important for students to be aware of as they attempt to regulate their learning, specifically around challenges. Due to the paucity of research on mental health and SRL, there are many opportunities for future research to examine the interplay of SRL and PWB or mental health at university for student success. Importantly, as students may benefit from extending their metacognitive awareness to their engagement and PWB while learning, interventions should be designed with both students and researchers in mind.

By examining the process mining maps of two students, we were able to see patterns in students' PWB, engagement, challenges, and strategies over nine weeks. Molenaar et al. (2019) found providing elementary students with personalized visualizations based on their learning improved regulating practice behaviour, learning transfer, and relative monitoring accuracy. Thus, even though we did not show students their maps in this study, future research could show students their process mining maps of their learning. Importantly, this process needs to be supported by SRL as performance feedback alone is not always sufficient for students to translate their data into increased engagement in SRL (Butler \& Winne, 1995). For example, students may be able to realize they are not engaged in their courses or attaining their goals, or they may recognize their PWB is also lower, and select a course of action. Alternatively, if students realize their PWB is low, this could help them to see the connection between their PWB, engagement, and/or goal attainment. This metacognitive awareness could also help students employ different strategies, such as revisiting their task perceptions, or revising their goals. When students engage in weekly regulatory planning and reflection, assessing their own PWB and engagement may provide easy access for students to take this data, examine it, and make changes as necessary. Specifically, visualizations of adaptive and maladaptive regulation patterns, such as through process mining maps, may help students identify for themselves where and when to make changes.

\subsection{Limitations}

This study examined data from one semester of an undergraduate elective learning-to-learn course and may not be generalizable to other courses. Students in this course could have been actively making changes to their learning approaches, potentially affecting the findings. Future research could examine the interplay between PWB and SRL in other undergraduate courses to see how student' regulatory responses vary when they are not taking a course on how to effectively manage their SRL processes and strategies. Also, this study only examined one aspect of mental health, PWB, rather than all three aspects of psychological, social, and emotional well-being. Understanding students' PWB at university is a salient issue. However, as PWB is only one part of mental health, considering all aspects of mental health may further help students increase their self-awareness and success simultaneously. Future research could use a comprehensive mental health scale, such as the Mental Health Continuum-Short Form (MHC-SF; Keyes, 2009) to investigate further the interplay between the three factors of mental health and SRL. Next, only two students' process maps were examined for within-person differences. This limits the generalizability of the findings but does create opportunities for designing visualizations to assist students who are trying to improve either their learning approaches, their PWB and/or mental health, or both. This study relied on self-reported data only. This is important as this data can be useful for students to reflect on their own learning, but future research should incorporate objective data (e.g., trace data) to triangulate results. In particular, we relied on students' self-reported data of their goal attainment and even students in the low group were reported attaining goals most of the time (see Figure 3). While students' perceptions of their own learning are salient in SRL and student success, triangulating other objective goal attainment data would be prudent. 
Finally, the very moderate reliability for the academic engagement measure, indicating there may be a large error variance. The purpose of this measure was a weekly checklist where students could indicate whether or not they engaged in the specific behaviour (e.g., attended classes), however caution should be exercised in interpreting the findings of this measure due to the measurement error present.

\section{Conclusion}

In sum, to tackle the bigger issue of mental health at university, this study indicates students who report attaining their goals more often also have higher PWB. Leveraging SRL processes and strategies around academic challenges may also help students' PWB and engagement or vice versa. As engagement and PWB fluctuate over time, being aware of regulatory patterns may help students engage in more metacognitive control and strategic action. This is because, for students to be active in their SRL, they need ways to record and track data about their learning in order to identify patterns, monitor their approaches, and make adaptations as necessary (Winne, 2005). Self-regulating learners already regulate their behaviour, cognition, motivation, and emotion to reach goals (Winne \& Hadwin, 1998), therefore extending their metacognitive awareness and control to their PWB may also be advantageous for student success. Finally, analyzing within-person patterns of PWB and SRL processes may offer the most opportunity for interventions with high utility and applicability by students to be successful at university.

\section{Keypoints}

- Students' mental health at university is a growing global concern.

- This study examines psychological well-being, one of the three factors of mental health, and SRL at university.

- Process mining maps provide valuable insight to psychological well-being and students' regulatory responses to academic challenges

\section{Acknowledgments}

This research was supported by a Social Sciences and Humanities Research Council (SSHRC) of Canada Insight Research Grant 435-2012-0529 (PI: Hadwin) and 435-2018-0440 (PI: Hadwin); and a SSHRC Doctoral Fellowship (S. K. Davis). We would also like to thank Ramin Rostampour for his creation of the process mining maps. 


\section{References}

American College Health Association (2018). American College Health Association-National College Health Assessment II: Undergraduate Student Reference Group Data Report Fall 2018. Silver Spring, MD: American College Health Association. Retrieved from: https://acha.org/documents/ncha/NCHA-

II_Fall_2018_Undergraduate_Reference_Group_Data_Report.pd

Bannert, M., Reimann, P., \& Sonnenberg, C. (2013). Process mining techniques for analysing patterns and strategies in students' self-regulated learning. Metacognition and Learning, 9, 161185. https://doi.org/10.1007/s11409-013-9107-6

Boudreaux, M. J., \& Ozer, D. J. (2013). Goal conflict, goal striving, and psychological wellbeing. Motivation and Emotion, 37, 433-443. https://doi.org/10.1007/s11031-012-9333-2

Brackney, B. E. \& Karabenick, S. A. (1995). Psychopathology and academic performance: The role of motivation and learning strategies. Journal of Counseling Psychology, 42(4), 456465. https://doi.org/10.1037/0022-0167.42.4.456

Burris, J. L., Brechting, E. H., Salsman, J., \& Carlson, C. R. (2009). Factors associated with the psychological well-being and distress of university students. Journal of American College Health, 57(5), 536-544. https://doi.org/10.3200/JACH.57.5.536-544

Butler, D.L. and Winne, P.H. (1995). Feedback and self-regulated learning: A theoretical synthesis. Review of Educational Research, 65(3),245-281. https://doi.org/10.3102/00346543065003245

Conley, C. S., Durlak, J. A., \& Kirsch, A. C. (2015). A meta-analysis of universal mental health prevention programs for higher education students. Prevention Science, 16, 487-507. https://doi.org/10.1007/s11121-015-0543-1

Deci, E. L., \& Ryan, R. M. (2008). Facilitating optimal motivation and psychological well-being across life's domains. Canadian Psychology, 49(1), 14. https://doi.org/10.1037/0708-5591.49.1.14

De Coninck, D., Matthijs, K., \& Luyten, P. (2019). Subjective well-being among first-year university students: A two-wave prospective study in Flanders, Belgium. Student Success, 10(1), 33-45. https://doi.org/10.5204/ssj.v10i1.642

Diener, E., Wirtz, D., Tov, W., Kim-Prieto, C., Choi, D., Oishi, S., \& Biswas-Diener, R. (2010). New well-being measures: Short scales to assess flourishing and positive and negative feelings. Social Indicators Research, 97(2), 143-156. https://doi.org/10.1007/s11205-009-9493-y

Grunschel, C., Schwinger, M., Steinmayr, R., \& Fries, S. (2016). Effects of using motivational regulation strategies on students' academic procrastination, academic performance, and well$\begin{array}{llll}\text { being. Learning and Individual } & \text { Differences, } & 49, & 162-170 .\end{array}$ https://doi.org/10.1016/j.lindif.2016.06.008

Fredricks, J. A., Blumenfeld, P. C., \& Paris, A. (2004). School engagement: Potential of the concept: State of the evidence. Review of Educational Research, 74(1), 59-119. https://doi.org/10.3102\%2F00346543074001059

Hadwin, A. F., \& Winne, P. H. (2012). Promoting learning skills in undergraduate students. In M. J. Lawson \& J. R. Kirby (Eds.), The quality of learning: Dispositions, instruction, and mental structures (pp. 201-227). Cambridge University Press. https://doi.org/10.1017/CBO9781139048224.013

Hadwin, A. F., Davis, S. K., Bakhtiar, A., \& Winne, P.H. (2019). Academic challenges as opportunities to learn to self-regulate learning. In H. Askell-Williams \& J. Orrell (Eds). Problem solving for teaching and learning book: A festschrift for Emeritus Professor Mike Lawson (pp. 34-48). Routledge. https://doi.org/10.4324/9780429400902

Hills, P. \& Argyle, M. (2001). Emotional stability as a major dimension of happiness. Personality and Individual Differences, 31(8), 1357-1364. https://doi.org/10.1016/S0191-8869(00)00229-4

Howell, A. J. (2009). Flourishing: Achievement-related correlates of students' well-being. The Journal of Positive Psychology, 4(1), 1-13. https://doi.org/10.1080/17439760802043459

Keyes, C. L. M. (2002). The mental health continuum: From languishing to flourishing in life. Journal of Health and Social Behavior, 43(2), 207-222. https://doi.org/10.2307/3090197

Keyes, C. L. M. (2005). Mental illness and/or mental health? Investigating axioms of the complete state model of health. Journal of Consulting and Clinical Psychology, 73(3), 539548. https://doi.org/10.1037/0022-006X.73.3.539 
Keyes, C. L. M. (2009). Atlanta: Brief description of the mental health continuum short form (MHC-SF). Retrieved from: https://www.aacu.org/sites/default/files/MHC-SFEnglish.pdf

Keyes, C. L. M. (2013). Promoting and protecting positive mental health: Early and often throughout the lifespan. In C. L. M. Keyes (Ed.) Mental well-being: International contributions to the study of positive mental health (pp. 3-28). Springer Netherlands. https://doi.org/10.1007/978-94-0075195-8

Kilgo, C. A., Mollet, A. L., \& Pascarella, E. T. (2016). The estimated effects of college student involvement on psychological well-being. Journal of College Student Development, 57(8), 10431049. https://doi.org/10.1353/csd.2016.0098

Kuh, G. D., Kinzie, J., Buckley, J. A., Bridges, B. K., \& Hayek, J. C. (2007). Piecing together the student success puzzle: research, propositions, and recommendations. ASHE Higher Education Report (Vol. 32). John Wiley \& Sons. https://doi.org/10.1002/aehe.3205

Larcombe, W., Finch, S., Sore, R., Murray, C. M., Kentish, S., Mulder, R. A., Lee-Stecum, P., Baik, C., Tokatlidis, O. \& Williams, D. A. (2016) Prevalence and socio-demographic correlates of psychological distress among students at an Australian university, Studies in Higher Education, 41(6), 1074-1091. https://doi.org/10.1080/03075079.2014.966072

Molenaar, I., Horvers, A., Dijkstra, R., \& Baker, R.S. (2020). Personalized visualizations to promote young learners' SRL: the learning path app. In Proceedings of the Tenth International Conference on Learning Analytics \& Knowledge (LAK '20). Association for Computing Machinery, New York, NY, USA, 330-339. https://doi.org/10.1145/3375462.3375465

National Union of Students (2015). Mental health poll. Retrieved from: https://www.nusconnect.org.uk/resources/mental-health-poll-2015

Pintrich, P. R. (2004). A conceptual framework for assessing motivation and self-regulated learning in college students. Educational Psychology Review, 16, 385-407. https://doi.org/10.1007/s10648004-0006-x

Rogiers, A., Merchie, E., \& van Keer, H. Opening the black box of students' text-learning processes: A process mining perspective. Frontline Learning Research, 8(3), 40-62. https://doi.org/10.14786/flr.v8i3.527

Rückert, H. (2015). Students' mental health and psychological counselling in Europe. Mental Health \& Prevention, 3(1-2), 34-40. https://doi.org/10.1016/j.mhp.2015.04.006

Rush, J. \& Grouzet, F. M. E. (2012) It is about time: Daily relationships between temporal perspective and well-being, The Journal of Positive Psychology, 7(5), 427442. https://doi.org/10.1080/17439760.2012.713504

Ryan, R. M., \& Deci, E. L. (2001). On happiness and human potentials: A review of research on hedonic and eudaimonic well-being. Annual Review of Psychology, 52, 141166. https://doi.org/10.1146/annurev.psych.52.1.141

Ryan, R. M., Huta, V., \& Deci, E. L. (2008). Living well: A self-determination theory perspective on eudaimonia. Journal of Happiness Studies, 9, 139-170. https://doi.org/10.1007/s10902-0069023-4

Ryff, C. D., \& Keyes, C. L. M. (1995). The structure of psychological well-being revisited. Journal of Personality and Social Psychology, 69(4), 719-727. https://doi.org/10.1037/0022-3514.69.4.719

Ryff, C. D., \& Singer, B. (1998). The contours of positive human health. Psychological Inquiry, 9, 128. https://doi.org/10.1207/s15327965pli0901_1

Schmitz, B., Klug, J., \& Schmidt, M. (2011). Assessing self-regulated learning using diary measures with university students. In Zimmerman, B. J., Schunk, D. H. (Eds.), Handbook of self-regulation of learning and performance (pp. 251-266). Routledge. https://doi.org/10.4324/9780203839010.CH16

Schunk, D. H. \& Greene, J. A. (2018). Historical, contemporary, and future perspectives on selfregulated learning and performance. In D. H. Schunk \& J. A. Greene (Eds.), Handbook of selfregulation of learning and performance $\left(2^{\text {nd }} \mathrm{ed}.\right)$ (pp. 1-15). Routledge. https://doi.org/10.4324/9781315697048.CH1

van der Zanden, P. J. A. C, Denessen, E., Cillessen, A. H. N., \& Meijer, P. C. (2018). Domains and predictors of first-year student success: A systematic review. Educational Research Review, 23, 57-77. https://doi.org/10.1016/j.edurev.2018.01.001 
Van Nguyen, H., Laohasiriwong, W., Saengsuwan, J., Thinkhamrop, B., \& Wright, P. (2015). The relationships between the use of self-regulated learning strategies and depression among medical students: An accelerated prospective cohort study. Psychology, Health \& Medicine, 20(1), 59-70. https://doi.org/10.1080/13548506.2014.894640

Winne, P. H., \& Hadwin, A. F. (1998). Studying as self-regulated learning. In D. J. Hacker, J. Dunlosky, \& A. C. Graesser (Eds.), Metacognition in Educational Theory and Practice. (pp. 277-304). Lawrence Erlbaum. https://doi.org/10.4324/9781410602350-19

Winne, P. H. (2001). Self-regulated learning viewed from models of information processing (p. 164). In B. J. Zimmerman \& D. H. Schunk (Eds.), Self-regulated learning and academic achievement: Theoretical perspectives ( $2^{\text {nd }}$ ed., $\quad$ pp.153-189). $\quad$ Lawrence Erlbaum. https://doi.org/10.1007/978-1-4612-3618-4

Winne, P. H. (2005). A perspective on state-of-the-art research on self-regulated learning. Instructional Science, 33, 559-565. https://doi.org/10.1007/s11251-005-1280-9

World Health Organization. (2016). Mental health: Strengthening our response. [Fact Sheet]. Retrieved from: http://www.who.int/mediacentre/factsheets/fs220/en/

Yorke, M., \& Longden, B. (2008). The first-year experience of higher education in the UK. York: Higher Education Academy.

Retrieved from: https://www.heacademy.ac.uk/system/files/fyefinalreport 0.pdf

Zimmerman, B. J. (1989). A social cognitive view of self-regulated academic learning. Journal of Educational Psychology, 81(3), 329-339. https://doi.org/10.1037/0022-0663.81.3.329

Zimmerman, B. J., \& Martinez-Pons, M. (1990). Student differences in self-regulated learning: Relating grade, sex, and giftedness to self-efficacy and strategy use. Journal of Educational Psychology, 82(1), 51-59. https://doi.org/10.1037//0022-0663.82.1.51

Zimmerman, B. J. \& Schunk, D. H. (Eds.) (2001). Self-regulated learning and academic achievement: Theoretical perspectives ( $2^{\text {nd }}$ Ed.). Lawrence Erlbaum. https://doi.org/10.1007/978-1-4612$3618-4$

Academic engagement items

\section{Appendix A: Measures}

\begin{tabular}{ll}
\hline \multicolumn{1}{c}{ Item } & Response \\
\hline I attended all classes in my courses & Yes/No \\
I met all my deadlines in all my courses & Yes/No \\
I did all my assignments in my courses & Yes/No \\
I completed all the assigned readings in my courses & Yes/No \\
I asked for help when I didn't understand something in my courses & Yes/No \\
I tried to summarize what I learned in my courses & Yes/No \\
\hline
\end{tabular}

Psychological well-being items (adapted from Rush \& Grouzet, 2012)

\section{How am I doing this week?}

\section{Likert Scale}

I feel grounded in who I am and where I am going

I feel supported by people in my life and classes

I am engaged and interested in my activities

I have encouraged people in my life and classes

I feel competent and capable in my activities

I feel alive and energized

1 Not at all

4 Moderately

Life is good

7 Very much

I feel successful in my courses

I am successfully adapting to new challenges 